\title{
Deteriorating Cost-Benefit Ratios for Ecstasy/MDMA with Repeated Usage
}

\author{
A. O’Sullivan ${ }^{1}$ and A.C. Parrott ${ }^{*}, 1,2$
}

${ }^{I}$ School of Psychology, University of East London. London, UK

${ }^{2}$ Department of Psychology, Swansea University, Wales, UK

Keywords: MDMA, ecstasy, tolerance, mood state, cost benefit ratio, stress, recreational drug.

\section{INTRODUCTION}

The aim was to measure the positive gain scores, and negative side-effect scores reported by recreational Ecstasy/MDMA users. Self-rating scores for the first and last times on Ecstasy were compared, allowing the change in cost-benefit ratios to be calculated. The utility of cost-benefit ratios for human psychopharmacology is debated in [1]. assessed on an identical scale. One-way between group ANOVAs were calculated for each question.

\section{RESULTS}

Every group reported a positive cost-benefit ratio the first time they took Ecstasy, showing that positive gains outweighed negative experiences. However the light/novice users, who had taken Ecstasy/MDMA just a few times before

Table 1. Group Mean Scores for Positive and Negative Ecstasy/MDMA Effects, for the First and Last Times on Drug $(1=$ Minimum, 10 = Maximum)

\begin{tabular}{|c|c|c|c|c|c|}
\hline Sample size (N) & 18 & 10 & 22 & 18 & - \\
\hline Positive effects first time & 4.9 & 6.6 & 8.6 & 8.8 & $\mathrm{~F}=12.22, \mathrm{p}<0.001$ \\
\hline Positive effects last time & 3.9 & 6.2 & 3.4 & 4.3 & $\mathrm{~F}=4.40, \mathrm{p}<0.01$ \\
\hline Negative effects first time & 3.6 & 3.2 & 3.9 & 2.9 & $\mathrm{~F}=0.55$, non-sig \\
\hline Negative effects last time & 5.8 & 4.2 & 5.3 & 5.0 & $\mathrm{~F}=0.66$, non-sig \\
\hline $\begin{array}{l}\text { Increase in negative effects: } \\
\text { - from first to last time }\end{array}$ & +2.2 & +1.0 & +1.4 & +2.1 & - \\
\hline Cost-Benefit ratio first time & $+36 \%$ & $+103 \%$ & $+120 \%$ & $+203 \%$ & - \\
\hline
\end{tabular}

\section{METHODS}

68 recreational Ecstasy/MDMA users were categorized into four subgroups: light versus heavy users $(+20$ occasions lifetime), subdivided into current and former users (usage within 6 months). Each unpaid volunteer completed a questionnaire about their personal experiences on Ecstasy/MDMA. The four questions here covered experiences the first and last times on Ecstasy. Positive effects were assessed using a ten-point rating scale from 1 (none) to 10 (maximum), while 'negative' effects were

*Address correspondence to this author at the Department of Psychology, University of Swansea, Swansea SA2 8PP, Wales, UK; Tel: $+44(0) 1792$ 295271; Fax: +44(0)1792 295679; E-mail: a.c.parrott@swansea.ac.uk quitting, showed lower 'positive' drug scores and lower costbenefit ratios. The other three groups reported higher positive scores, and larger cost-benefit ratios, for their first Ecstasy experience (Table 1). The other main finding was the universal decline in positive ratings from the first Ecstasy experience to the last. Every subgroup showed these changes, although they occurred to different extents. The heavy user subgroups, who had taken most drug overall, showed the greatest decline in positive experiences (Table 1). Negative experience scores did no differ between groups at either time period, although there was a universal increase in negative ratings over time. Every group demonstrated a decline in cost-benefit ratio with continued MDMA usage, although this decline was greatest for the most experienced users. 


\section{DISCUSSION}

The less euphoric MDMA reactions of light/novice quitters may provide a reason for their taking it on just a few occasions. This agrees with Degenhardt et al. [2] who noted: 'At the individual level, many of those who experiment find the effects aversive and do not persist'. It also confirms the variance in mood reactions to MDMA [3-5], and the adverse mood states afterwards [6]. The universal decline in positive ratings with repeated Ecstasy, was consistent with previous reports of decline in efficacy [7], and is consistent with chronic pharmacodynamic tolerance [8]. The only group to still report a positive cost-benefit ratio to their most recent Ecstasy experience, with more gains than losses, was current light/novice users. Both groups of experienced users reported negative cost-benefit ratios, with former heavy users having the worst scores overall (Table 1). This is consistent with the personal descriptions of some heavy/experienced users, who report that as they 'lose the magic' and experience more side-effects, they take MDMA less frequently, before quitting permanently [9].

\section{CONCLUSIONS}

The frequency of MDMA use tends to decline over time [10], a pattern which is almost unique amongst recreational drugs [8]. The present findings suggest that may be due to a declining cost-benefit ratio with repeated MDMA usage.
Hence recreational users may quit taking MDMA because it becomes more aversive than pleasurable.

\section{REFERENCES}

[1] Parrott A, Morinan A, Moss M, Scholey A. Understanding drugs and behaviour. Wiley: Chichester 2004.

[2] Degenhardt L, Copeland J, Dillon P. Recent trends in the use of "club drugs": an Australian review. Subst Use Misuse 2005; 40: 1241-56.

[3] Greer G, Tolbert R. Subjective reports of the effects of MDMA in a clinical setting. J Psychoactive Drugs 1986; 18: 319-27.

[4] Liechti ME, Gamma A, Vollenweider FX. Gender differences in the subjective effects of MDMA. Psychopharmacology 2001; 154: 161-8.

[5] Parrott AC. The psychotherapeutic potential of MDMA (3,4methylenedioxymethamphetamine): an evidence-based review. Psychopharmacology 2007; 191: 181-93.

[6] Parrott AC, Lasky J. Ecstasy (MDMA) effects upon mood and cognition; before, during, and after a Saturday night dance. Psychopharmacology1998; 139: 261-8.

[7] Peroutka SJ, Newman H, Harris H. Subjective effects of 3,4methylenedioxymethamphetamine in recreational users. Neuropsychopharmacology 1988; 1: 273-7.

[8] Parrott AC. Chronic tolerance to recreational MDMA (3,4methylenedioxymethamphetamine) or Ecstasy. J Psychopharmacol 2005; 19: 71-83.

[9] Parrott AC. Conscious awareness $v s$ optimistic beliefs in recreational Ecstasy/MDMA users. In: Perry, E, Ashton WE, et al., Eds. The Neuroscience of consciousness. Amsterdam: Williams \& Co 2010.

[10] Verheyden SL, Henry JA, Curran HV. Acute, sub-acute and longterm subjective consequences of 'ecstasy' (MDMA) consumption in 430 regular users. Hum Psychopharmacol 2003; 18: 507-17. 